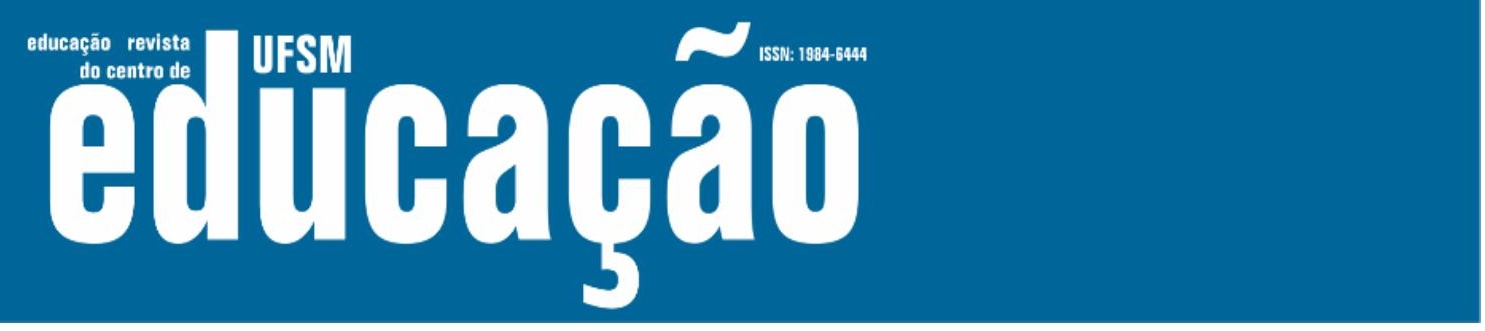

ISSN: 1984-6444 | http://dx.doi.org/10.5902/1984644433299

\title{
A Escola Nova e o Método Intuitivo nos programas de ensino da Escola Normal Superior Vocacional (1937) em Santa Catarina
}

The New School and the Intuitive Method in the teaching programs of the Normal Higher Vocational School (1937) in Santa Catarina

Ana Paola Sganderla

Professora Doutora na Universidade Centro do Centro -Oeste e na Universidade Estadual de Ponta Grossa, Paraná.

anapaolas@gmail.com - https://orcid.org/0000-0003-4602-9717

Diana Carvalho de Carvalho

Professora doutora na Universidade Federal de Santa Catarina.

dianacc@terra.com.br - https:orcid.org/0000-0002-6924-2214

Recebido em 26 de junho de 2018

Aprovado em 10 de junho de 2019

Publicado em 29 de março de 2020

\section{RESUMO}

O artigo em tela analisa os programas de ensino de Psicologia, Pedagogia e História da Educação propostos para a Escola Normal Superior Vocacional em Santa Catarina, por meio do Decreto n. 217, de 9 de março de 1937. O objetivo será problematizar a coexistência de conteúdos referentes ao método intuitivo e de conhecimentos escolanovistas em diferentes disciplinas. A utilização e o ensino do método intuitivo/lição das coisas fundamentou a reforma de ensino catarinense de 1911, sendo adotado como princípio orientador da educação no estado e assim permaneceu adentrando os anos 1930, momento que em que eram difundidos e estudados os conhecimentos da Escola Nova, indicando que estas duas orientações assumiram centralidade na formação teórico-prática do futuro docente. A perspectiva empirista parece ter sido um dos fundamentos que orientou as discussões educacionais do contexto da época, desde os pareceres de Rui Barbosa sobre o ensino até as ideias de Lourenço Filho na obra Introdução ao estudo da Escola Nova. Nos programas de 1937, as questões que envolviam a aprendizagem, a motivação e as diferenças individuais dos estudantes pautavam-se nessa perspectiva teórica, sendo a aposta na formação da mentalidade científica do professor.

Palavras-chave: Formação de professores; Escola Nova; Método Intuitivo.

\section{ABSTRACT}

The article on screen analyzes the educational programs of Psychology, Pedagogy and History of Education proposed for the Normal Higher Vocational School in Santa 


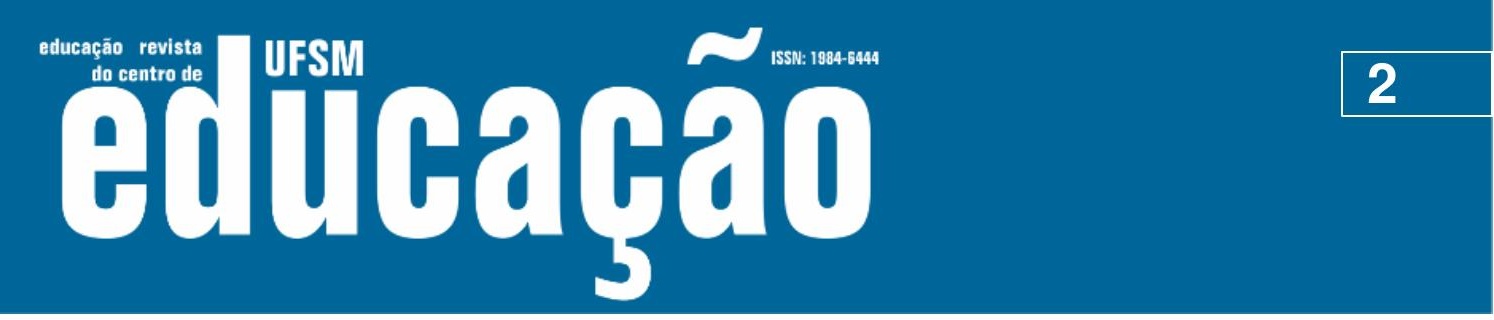

ISSN: 1984-6444 | http://dx.doi.org/10.5902/1984644433299

Catarina, through Decree n. 217, of March 9, 1937. The objective will be to problematize the coexistence of contents referring to the intuitive method and of scholastic knowledge in different disciplines. The use and teaching of the intuitive method / lesson of things founded the reform of teaching in Santa Catarina in 1911, being adopted as a guiding principle of education in the state and thus remained in the 1930s, at which time the knowledge of the School was disseminated and studied Nova, indicating that these two orientations assumed centrality in the theoretical-practical formation of the future teacher. The empiricist perspective seems to have been one of the foundations that guided the educational discussions of the context of the time, from the opinions of Rui Barbosa on teaching to the ideas of Lourenço Filho in the work Introduction to the study of the New School. In the 1937 programs, questions that involved students' learning, motivation, and individual differences were based on this theoretical perspective, with a focus on the formation of the teacher's scientific mindset. Keywords: Teacher's formation; New school; Intuitive Method.

\section{Introdução}

Nosso foco de análise nesse artigo são os programas de ensino de Psicologia, Pedagogia e História da Educação propostos para a Escola Normal Superior Vocacional em Santa Catarina, por meio do Decreto n. 217, de 9 de março de 1937.

Embora se observem iniciativas para a formação de professores em Santa Catarina desde o final do século XIX, é somente em 1911, com a Reforma implantada por Orestes Guimarães, que a Escola Normal se consolida ${ }^{1}$. Tal reforma teve por objetivo a organização e ampliação do ensino primário, sendo suas primeiras atenções dirigidas ao ensino normal, reestruturando a Escola Normal Catarinense, única instituição existente até então para a formação dos professores do Estado. Foram renovados os espaços, os tempos, as normas, os conteúdos e as práticas escolares, visando à formação do professor moderno: "A seleção de novas disciplinas, conteúdos e práticas escolares, ancoradas nas ciências e nos valores republicanos da moral, do civismo e do patriotismo, deveriam conformar um moderno professor com competência para instruir e educar as classes populares." (TEIVE E DALLABRIDA, 2011, p.16).

A reforma foi encabeçada pelo professor paulista Orestes Guimarães e o método intuitivo/lições das coisas foi adotado como princípio orientador na Educação 


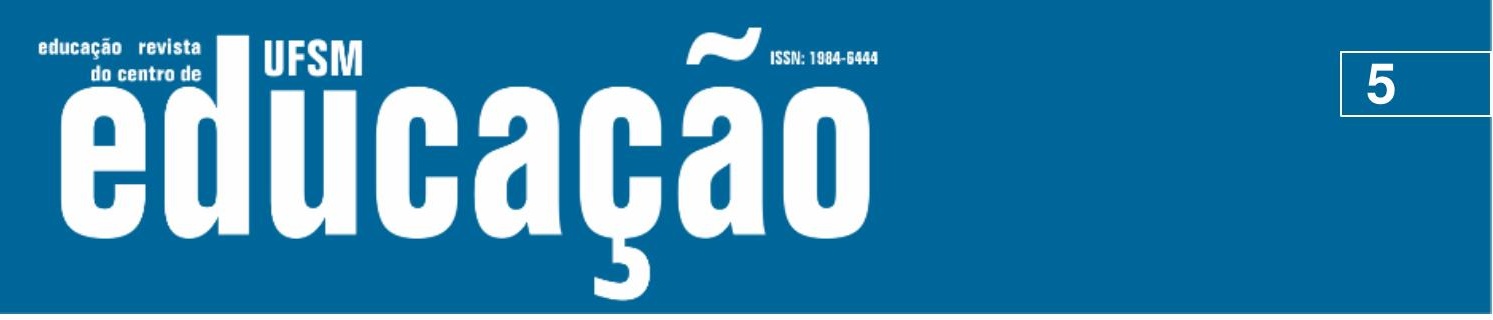

ISSN: 1984-6444 | http://dx.doi.org/10.5902/1984644433299

Buscamos neste cenário aprofundar a compreensão da relação entre o método intuitivo e os pressupostos da Escola Nova, com base na análise dos programas em pauta.

\section{Sobre o método intuitivo e a Escola Nova}

Segundo Valdemarin (2004), as discussões sobre o método intuitivo estão presentes nos debates educacionais do final do século XIX, inserindo-se no movimento de inovações e criação de um sistema de ensino na realidade brasileira e sendo adotado como referência em escolas européias e americanas.

Ao comentar a tradução que Rui Barbosa faz, em 1881, do manual americano Primeiras Lições de Coisas, de Norman Allison Calkins, a autora destaca que:

(...) Rui Barbosa - homem culto e, naquele momento, dedicado ao estudo de questões educacionais - certamente acompanhava a valorização imputada à renovação dos métodos de ensino, uma vez que o método intuitivo é concebido por seus elaboradores como um poderoso instrumento pedagógico, capaz de modernizar o ensino e, principalmente, formar estudantes mais adequados às transformações políticas e econômicas, em curso nas décadas finais do século XIX. (VALDEMARIN, 2004, p. 02)

$\mathrm{Na}$ investigação que realiza sobre o manual, a autora identifica o referencial teórico que fundamenta o método intuitivo: as formulações de Pestalozzi e Froebel e o empirismo, especialmente as teorizações sobre o conhecimento elaboradas por Francis Bacon, John Locke e David Hume, nos séculos XVII e XVIII. Nessa perspectiva, os sentidos são considerados o ponto de partida para o conhecimento, sendo o objetivo principal do método:

(...) iniciar os alunos no uso dos sentidos para a obtenção do conhecimento, de modo que passe da intuição dos sentidos para a intuição intelectual, preparando-os para adquirir ideias novas. Esse método habitua o aluno, pouco a pouco, a ver por si mesmo e ele poderá, depois de sair da escola, aumentar seus conhecimentos e suas observações, aplicar suas faculdades a um estudo determinado (VALDEMARIN, 2004, p. 41).

Sobre o modelo social que o orienta, assim se manifesta a autora: 


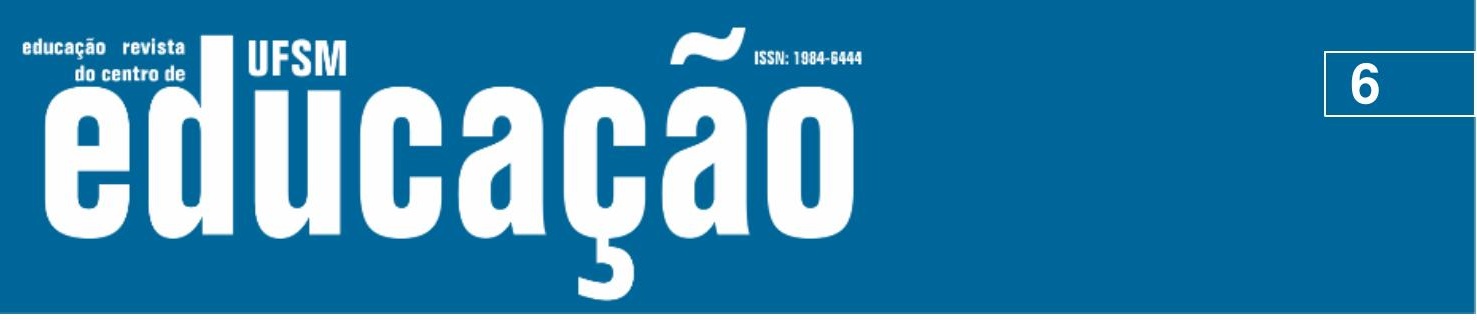

ISSN: 1984-6444 | http://dx.doi.org/10.5902/1984644433299

Iniciando as lições sobre as formas com objetos presentes no cotidiano da criança, o programa de ensino progride até chegar a objetos industrializados ou elementos naturais, isto é, fabricados ou postos a serviço do homem. Nessa sequência de lições, é possível identificar a ênfase dada a um modelo social específico, qual seja, aquele pautado no trabalho industrial, portador de um modelo formativo que tem a racionalidade e a produção de objetos e mercadorias como seus valores prioritários (VALDEMARIN, 2004, p. 130).

No Brasil, uma das primeiras defesas do método intuitivo foi feita por Rui Barbosa nos pareceres que elaborou sobre a reforma de Leôncio de Carvalho, em 1882, na qualidade de relator da comissão de instrução pública da Câmara. É sobre esses pareceres que Lourenço Filho se debruça na obra A Pedagogia de Rui Barbosa (LOURENÇO FILHO, 1954/2001)³. Considerando a importância de Lourenço Filho para a inserção da Psicologia na constituição do campo educacional brasileiro (SGANDERLA, 2007; SGANDERLA e CARVALHO, 2008 e SGANDERLA e CARVALHO, 2010), bem como para a organização e difusão dos conhecimentos sobre a Escola Nova no país (LOURENÇO FILHO, 1930/20024), parece-nos significativa sua análise acerca da obra de Rui Barbosa.

Lourenço Filho chama a atenção para o fato de que os pareceres de Rui Barbosa e sua tradução da obra de Calkins vinham “(...) documentar uma nova direção pedagógica, novo espírito, tal como se elaborava em mais adiantados países, e com o qual ele punha em contato, pela primeira vez, os mestres brasileiros" (LOURENÇO FILHO, 1954/2001, p. 84).

Ao buscar identificar as fontes que fundamentaram os pareceres, Lourenço Filho sintetiza quatro tipos de fontes que influenciaram Rui Barbosa: a) fontes gerais com base em estudos da história e crítica histórica, pensamento social e teoria política, filosofia sistemática; b) fontes especiais fundamentadas na Biologia, Psicologia e Sociologia; c) fontes de matéria pedagógica integrada, que envolvem fundamentos do método, orientação didática, organização e administração escolar; d) fontes documentárias, que dizem respeito ao ensino e questões sociais no Brasil e em outros países.

O estudo realizado por Lourenço Filho evidencia que Rui Barbosa encarava a educação como uma questão política e cultural, para além de propostas educacionais imediatas, ou seja, como ponto estratégico para a constituição da nação brasileira em 


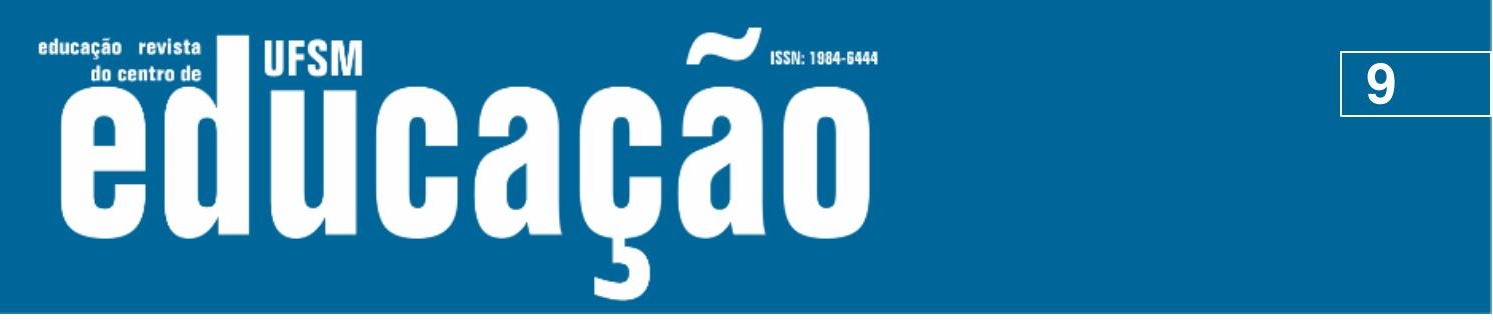

ISSN: 1984-6444 | http://dx.doi.org/10.5902/1984644433299

foi colocado na tarefa social e nacional a que se destinava a escola, ou seja, no seu papel cívico e social.

A polêmica sobre as diferenças entre Escola Nova e Escola Ativa é objeto de análise de Marta Carvalho (2002) quando a autora trata das representações sobre a criança, presentes nas discussões educacionais na primeira república. A autora retoma questionamentos dos educadores da época sobre quais seriam as diferenças entre as propostas desenvolvidas nas reformas estaduais (por exemplo, a reforma realizada no Estado do Ceará, por Lourenço Filho, em 1922), e as propostas defendidas no âmbito da Escola Nova.

Marta Carvalho (2002) reproduz o questionamento de João Hippolyto, diretor da Escola Normal quando Lourenço Filho foi reformador da instrução pública do Ceará, em 1922, sobre as críticas que tinha recebido do novo Diretor da Instrução Pública com relação à reforma que ambos haviam empreendido na época:

\begin{abstract}
A indignação de João Hippolyto era justificada. Afinal, não havia sido ele o colaborador de Lourenço em uma reforma vazada nos princípios da escola ativa? Na carta dirigida à Lourenço, perguntava: a reforma da Instrução Pública que ele promovera no Ceará, com a sua colaboração, no início da década, podia ser considerada uma reforma segundo os preceitos da pedagogia da escola nova? Ou teria sido concebida nos marcos da velha pedagogia? Era ela "escola ativa"? (CARVALHO, 2002, p. 385).
\end{abstract}

$\mathrm{Na}$ resposta de Lourenço Filho aos questionamentos recebidos, o autor expressa que o método intuitivo levou séculos para ser implantado, mas estava sendo substituído a partir do início do século XX:

Do começo deste século para cá, essa concepção tende a ser substituída por outra, a de uma filosofia pragmatista (a verdade é a utilidade), e de uma filosofia vitalista (além das impressões sensoriais há um QI, em cada indivíduo, que plasma as ideias a sua feição). O próprio pensamento para essa escola é ação: ação reduzida, mas ação. Ação reduzida e sistematizada pela linguagem, mas atividade. Daí como consequência, não se pretende ensinar mais tão somente pela ação das coisas, mas pela ação do indivíduo, único capaz de organizar o espírito solidamente, para seu fim normal: dirigir a ação. (LOURENÇO FILHO apud CARVALHO, 2002, p. 385-386).

Lourenço Filho destacava que o foco das mudanças deveria ser dirigido à mentalidade dos professores, promovendo uma nova cultura pedagógica que tomaria por base os conhecimentos científicos para dirigir a ação docente: 


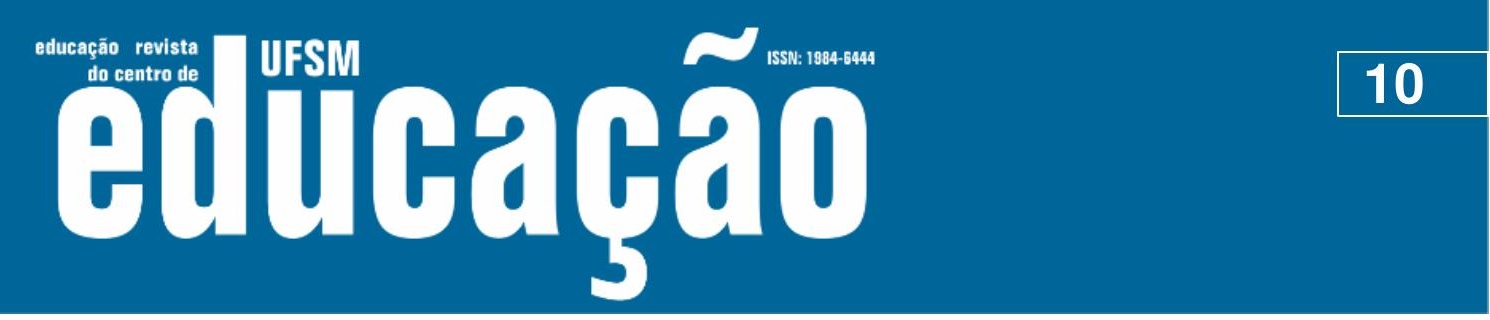

ISSN: 1984-6444 | http://dx.doi.org/10.5902/1984644433299

(...)Ter programas de centro de interesse, fazer excursões e outras práticas mais ou menos ativas, sem mudança porém da mentalidade do professor e sem a compreensão da nova psicologia do comportamento (o behaviorismo dos americanos) pode degenerar em anarquia e diminuição do ensino. Será substituir uma rotina por outras, com essa desvantagem: da mais velha sabese o que é que dá. Dá nova ninguém pode afirmar. (LOURENÇO FILHO apud CARVALHO, 2002, p.386).

A resposta de Lourenço Filho deixa clara a perspectiva teórica que se torna hegemônica em sua defesa da Escola Nova e também estava presente desde os pareceres de Rui Barbosa: o empirismo.

\section{Os programas de ensino}

Sganderla (2015), ao analisar o programa de Psicologia da Escola Normal Catarinense, em 1911, destaca a educação dos sentidos como um item central, bem como a necessidade de conhecer a natureza psíquica da criança. Entre esses conteúdos, podemos destacar: inteligência, memória, percepção, atenção, vontade, curiosidade, atividade.

Os conteúdos que compunham a cadeira de Psicologia e Pedagogia estão transcritos no quadro 02 seguir, tendo por base o Decreto n586, de 22.04.1911, que definia Programa e horário da Escola Normal Catarinense:

Quadro 02 -Noções indispensáveis de Psicologia e Pedagogia - Psicologia 2º ano

\begin{tabular}{|l|l|}
\hline 01 & Objeto da psicologia. Seu lugar na ordem das ciências. Seu método sua utilidade \\
\hline 02 & $\begin{array}{l}\text { A sensibilidade. O prazer e a dor. As inclinaçães e sua classificação. Inclinações } \\
\text { pessoais: conservação, possessão, bem estar, independência e amor próprio }\end{array}$ \\
\hline 03 & Educação dos sentidos \\
\hline 04 & $\begin{array}{l}\text { A inteligência. Ideias das principais faculdades intelectuais. A percepção externa. } \\
\text { Educação da percepção }\end{array}$ \\
\hline 05 & A memória. Conservação. Espécies de memória e sua educação \\
\hline 06 & A atividade. Diversas espécies. Educação da vontade \\
\hline 07 & $\begin{array}{l}\text { A vontade. Seus limites e seu poder. Educação pessoal da vontade. A liberdade da } \\
\text { vontade. }\end{array}$ \\
\hline 08 & O instinto da curiosidade. Partido que se pode tirar dele. Não cansar a criança \\
\hline 09 & Tendências próprias para prender e desenvolver a atenção \\
\hline 10 & Papel do ensino máximo primário \\
\hline 11 & Necessidade de conhecer a natureza psíquica da criança \\
\hline 12 & A criança nervosa, triste, sensível, meios educativos \\
\hline
\end{tabular}

Fonte: SANTA CATARINA, 1911, p.21 


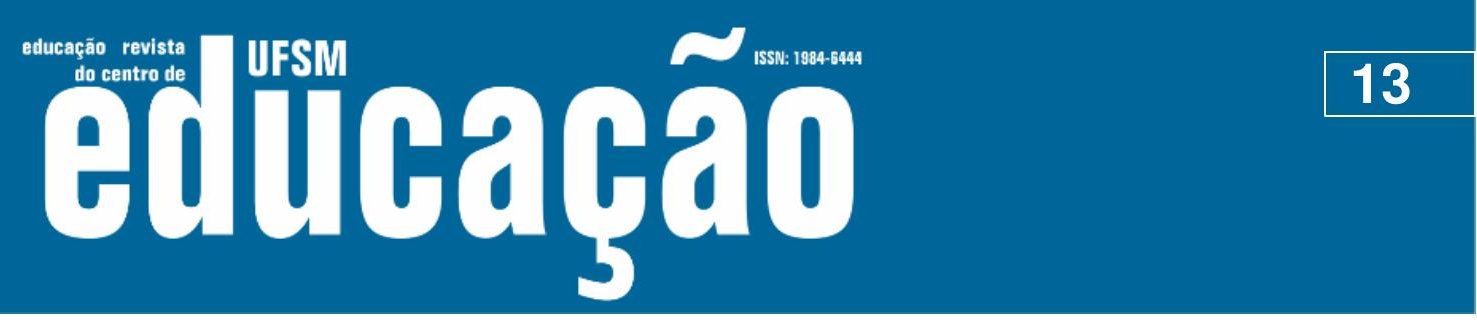

ISSN: 1984-6444 | http://dx.doi.org/10.5902/1984644433299

Francis Galton ${ }^{6}$ (1822-1911) foi um cientista inglês com fundamento evolucionista. Era primo de Darwin e se dedicou ao estudo da inteligência com base em estatísticas a fim de confirmar o papel da herança genética para o desenvolvimento das faculdades mentais:

Nossa constituição parece ser diretamente relacionada com as de nossos
antepassados. Nossos corpos, mentes e capacidades de desenvolvimento
são derivadas de nossos pais. Tudo o que possuímos ao nascer constitui
herança de nossos ancestrais. (GALTON, 1907, p.36 apud GOUVEA;
GERKEN, 2010, p. 99)

Galton desenvolveu uma teoria a partir da ideia de que a inteligência é herdada, e de que seria feita uma intervenção social com base na seleção dos mais capazes para o aprimoramento da raça. A eugenia foi fundada pelo autor, que acreditava e insistia na tese de que pais bem dotados teriam filhos com a mesma característica, embora ele próprio nunca os tenha tido. O cientista inglês pode ser considerado como precursor dos testes mentais que se baseavam em suas pesquisas na medição de caracteres anatomofisiológicos para o acesso/medição da inteligência, tendo sido um dos primeiros autores a utilizar a estatística para medição dos fenômenos humanos (GOUVEA; GERKEN, 2010).

As mudanças na escola e universidade norte americana, no início do século $X X$, se deveram ao final da Guerra Civil, ao desenvolvimento econômico e à imigração crescente que deveria manter-se pacificada. Era necessário construir um homem novo, e nesse cenário, as produções de Thornike (1874-1949) ${ }^{7}$ foram de extrema relevância, como comprova o texto a seguir:

Nesse ambiente de "americanização" do imigrante e do norte-americano por
meio da escola e do ensino, Thorndike mobiliza sua energia intelectual para
produzir instrumentos, manuais e testes, que educassem sujeitos capazes de
pensar, sentir e agir de forma eficiente e racional diante das transformações
econômicas, sociais e políticas por que passavam os Estados Unidos nas
primeiras décadas do século XX. (SANTOS, 2006, p.15)

Com base no comportamento manifesto, Thorndike entendia a aprendizagem como as conexões estabelecidas entre estímulo e resposta. As respostas poderiam ser pensamentos, sentimentos, ações e atitudes em conexão com as situações de vida. Nestas respostas estaria a organização inata do homem, mas a educação poderia perpetuar, eliminar ou modificar estas tendências. Assim sendo, 


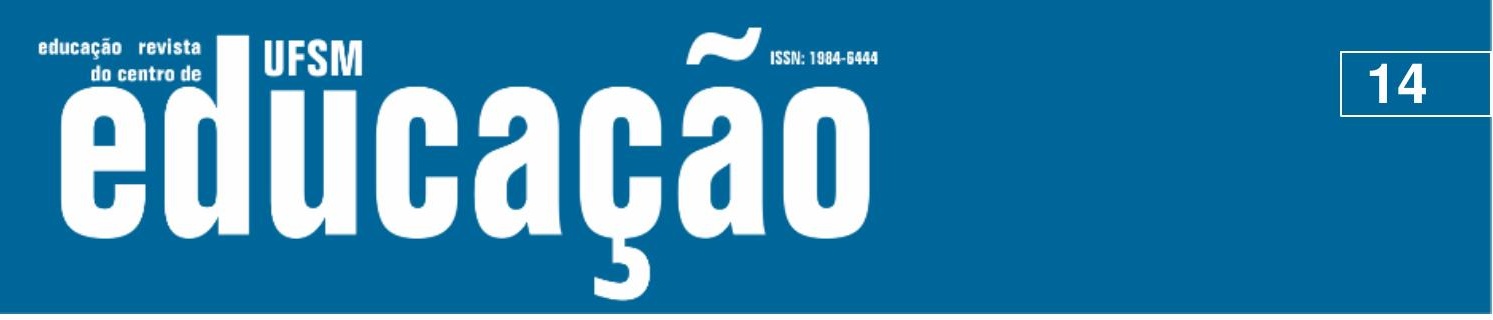

ISSN: 1984-6444 | http://dx.doi.org/10.5902/1984644433299

[...] por meio da educação, alguns elementos da natureza original do indivíduo são alterados com o objetivo de melhorá-los - a fim de produzir nele a informação, hábito, capacidade, interesse e ideais que são desejáveis. $O$ comportamento do homem na família, nos negócios, na religião e em outras ocupações da vida surge no equipamento original de instintos e capacidades. (SANTOS, 2006, p.139)

Dessa forma, as aprendizagens seriam as conexões que o homem estabelece ao longo da vida, em geral, ligadas à mesma ocorrência, em que um fato mental se liga a outro. O ensino, então, deveria organizar conexões que modificassem o que já se sabe e estabelecer vínculos entre os diferentes conhecimentos que se pretende ensinar. Em outras palavras:

Aprendizagem é conexão; e ensinar é a organização de situações que poderão conduzir ou moldar vínculos desejáveis ou fazê-los satisfatórios. Um volume poderá ser escrito mostrando, em detalhes, que vínculos em exercícios de aritmética, ortografia, Alemão, filosofia e outros, certos costumes e leis, certa moral e ensino religioso tendem a ser formados em um homem de dada natureza original; ou mostrar como certos vínculos desejados podem ser formados de maneira racionalizada. (THORNDIKE, 1913b, p. 55 apud SANTOS, 2006, p.142)

E a Psicologia da Aprendizagem seria a responsável por elucidar as conexões/os vínculos que levaram a determinada aprendizagem, reconhecendo o que já estava originalmente no homem e quais os vínculos que se formaram e que levaram às ações. Assim, seria possível controlar o comportamento e modificá-lo, pois já reconheceria as respostas dadas, suas conexões anteriores e as novas. O texto transcrito a seguir explica melhor o que afirmamos:

Para Thorndike (1930), a Psicologia da aprendizagem pode ter como finalidades: explanar como e onde começar, exatamente, esse processo a partir da definição do que é a natureza original do homem; prestar atenção nos vínculos que são formados e que causam no homem certas ações, devendo-se prestar mais atenção para esse aspecto do que para as características de certo objeto, tendo, dessa maneira, noção das respostas dadas a certo problema, pela satisfação ou rejeição dos mesmos; listar os vínculos e elementos dos vínculos que contam sobre os hábitos, associação de idéias, abstrações inferências etc.; medir a força de cada um dos vínculos, descobrir suas relações de facilitação e inibição; traçar a origem e prever possibilidade e efeitos delas na determinação de novos vínculos ou na modificação de velhos, formados por uma dada situação. (SANTOS, 2006, p.142)

Completando, podemos dizer que a Psicologia defendida por Thorndike seria capaz de entender o ser humano pelas conexões que realiza ao longo da vida, 


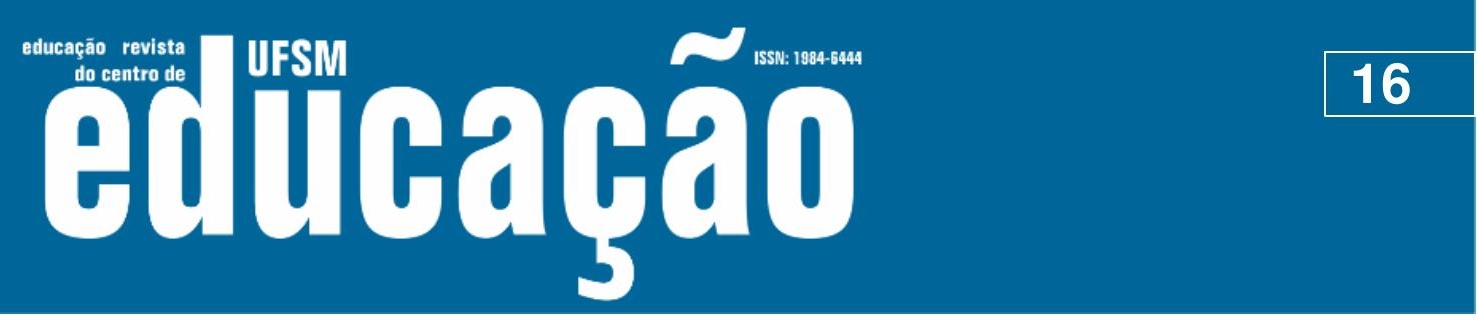

ISSN: 1984-6444 | http://dx.doi.org/10.5902/1984644433299

Segundo organização e o funcionamento do laboratório obedeciam ao plano de trabalho esboçado por Wundt. As atividades eram de dois tipos: de um lado, um curso introdutório para os novatos, com duração de um semestre, cujo objetivo era familiarizá-los com os instrumentos, métodos e técnicas experimentais; de outro, as atividades especiais dos membros antigos. No início de cada novo semestre, Wundt se reunia com esses membros para fixar os temas a serem investigados, levando em consideração o interesse de cada um pelos respectivos assuntos. Em seguida, os participantes eram divididos em grupos, cada grupo ficando responsável por um tema. Mas a adesão a um grupo era voluntária e cada membro podia participar de mais de um grupo. Para cada um dos grupos assim constituídos, era designado um líder - em geral um membro mais antigo do instituto, que já tinha mostrado sua capacidade em semestres anteriores -, cuja função era preparar os experimentos e, sempre que possível, redigir o relato final para publicação

Wundt é um exemplo significativo da Psicologia que se desenvolvia em diferentes laboratórios dedicados a esta ciência pelo mundo. A utilização de diferentes métodos de pesquisa refletia o movimento das diversas escolas de Psicologia, que os conceberam para análise psicológica do ser humano.

Em suas reflexões sobre este tema, Figueiredo (1991) assinala que praticamente toda a Psicologia que pretendia se constituir como uma ciência natural adotava um modelo instrumentalista dos fenômenos mentais e comportamentais, concebendo as funções mentais, como percepção e memória, como processos orientados à adaptação.

O desenvolvimento da Psicologia de caráter objetivo dá-se, como se viu com Wundt, na Europa, e vem suprir as demandas das sociedades industriais capitalistas, de selecionar, orientar, adaptar e racionalizar a produtividade visando, em última instância, a um aumento desta. Constata-se que as tendências experimentalistas e psicometristas não se opõem aos ditames das sociedades urbano-industriais capitalistas da época, ao contrário, as sacramentam cientificamente (CUNHA, 1995; PATTO, 1984), ao mesmo tempo em que esse contexto histórico contribuiu para a consolidação da Psicologia como campo científico.

No segundo ano do curso, a disciplina de Psicologia Educacional não centrava mais o estudo em correntes teóricas e seus representantes, mas tinha como foco temas em Psicologia e seus desdobramentos no âmbito educacional. O comportamento, suas manifestações e origem eram um dos temas centrais. Outros conteúdos que merecem destaque são: o estudo do aprendizado com suas teorias, 


\section{- Tusm AutthapaO

ISSN: 1984-6444 | http://dx.doi.org/10.5902/1984644433299

O exposto até aqui permite afirmar que os programas da Escola Normal em Santa Catarina incorporavam as discussões nacionais presentes naquele momento, bem como a produção de autores nacionais e internacionais, como é o caso de Lourenço Filho.

Embora tenhamos clareza de que, pela análise dos programas de ensino, não seja possível afirmar a influência dessas ideias na prática pedagógica dos professores, reconhecemos a importância de identificar a permanência de algumas ideias na história do pensamento educacional brasileiro. A perspectiva empirista parece ter sido um dos fundamentos que orientou as discussões educacionais do contexto da época, desde os pareceres de Rui Barbosa sobre o ensino até as ideias de Lourenço Filho na obra Introdução ao estudo da Escola Nova. Nos programas de 1937, as questões que envolviam a aprendizagem, a motivação e as diferenças individuais dos estudantes pautavam-se nessa perspectiva teórica. A aposta na ciência para estudo e diagnóstico das questões educacionais, por meio de instrumentos e procedimentos científicos, estava relacionada à defesa que os intelectuais da época faziam da eficiência e racionalidade para enfrentar as transformações que ocorriam na sociedade brasileira, tais como os desafios relativos ao progresso e à industrialização nascente. Na Educação, a aposta era na formação da mentalidade científica do professor.

\section{Referências}

ARAUJO, Saulo de Freitas. Wilhelm Wundt e a Fundação do Primeiro Centro Internacional de Formação de Psicólogos. Temas em Psicologia (Ribeirão Preto), v. 17, p. 3-8, 2009.

CARVALHO, Diana Carvalho de; DAROS, Maria das Dores; SGANDERLA, Ana Paola. Uma abordagem histórica da psicologia nos cursos de formação de professores: em foco os programas da disciplina em uma escola catarinense na década de 1930. Revista Brasileira de Educação (Impresso), v. 17, p. 675-692, 2012.

CARVALHO, Diana Carvalho de. A Psicologia diante da educação e do trabalho docente. Psicologia em estudo, UEM, 2002, v. 7, p. 51-60. 


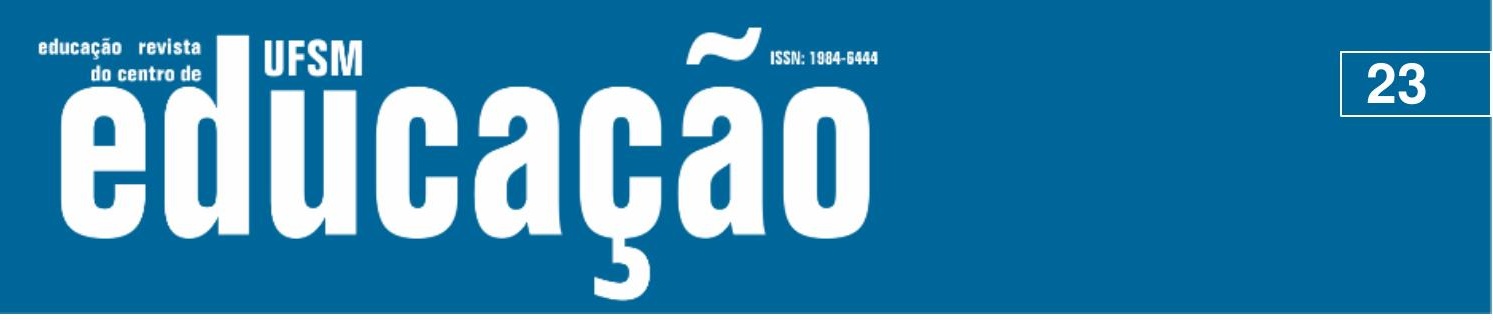

ISSN: 1984-6444 | http://dx.doi.org/10.5902/1984644433299

TEIVE, Gladys Mary Guizoni; DALLABRIDA, Norberto. A Escola da República: os grupos escolares e a modernização do ensino primário em Santa Catarina (19111918). 1. ed. Campinas, SP: Mercado de Letras, 2011

VALDEMARIN, Vera T. Estudando as lições de coisas. Campinas: Autores Associados, 2004.

WARDE, Mirian Jorge. G. Stanley Hall e o child study: Estados Unidos de fins do século XIX e começo do século XX. Revista Brasileira de História da Educação, v. 14, p. 243-270, 2014.

WARDE, Mirian Jorge. Para uma história disciplinar: psicologia, criança e pedagogia. In: Freitas, Marcos Cesar. (Org.). História social da infância no Brasil. São Paulo: Cortez, 1997, p. 289-310.

\section{Correspondência}

Ana Paola Sganderla - Universidade Federal de Santa Catarina - R. Eng. Agronômico Andrei Cristian Ferreira, s/n, CEP 88040-900, Trindade, Florianópolis, Santa Catarina, Brasil.

This work is licensed under a Creative Commons Attribution-NonCommercial 4.0 International (CC BY-NC 4.0)

\section{Notas}

\footnotetext{
${ }^{1}$ Sobre a trajetória da Escola Normal em Santa Catarina, consultar Daros e Daniel (2008), Schaffrath (1999) e Teive (2008).

${ }^{2}$ A reforma Trindade transformou a Escola Normal Catarinense em Instituto de Educação e teve como fundamento os conhecimentos escolanovistas. Fiori (1991) considera que o impacto das diversas modificações ocorridas na legislação nos anos de 1919, 1924 e 1928 sobre a realidade escolar e a mentalidade dos professores não foi comparável àquele obtido pela atuação de Orestes Guimarães na reforma de ensino de 1911.

${ }^{3} \mathrm{O}$ primeiro ano indicado é o ano da primeira publicação da obra, o segundo ano indicado é o da edição consultada, nesse caso a quarta edição, revista e ampliada.
}

${ }^{4}$ Lourenço Filho publicou a obra Introdução ao estudo da escola nova pela primeira vez em 1930, na coleção pedagógica Biblioteca da Educação, da qual era organizador. No presente artigo foi utilizada a $14^{\mathrm{a}}$ edição, publicada em 2002 pelo Conselho Federal de Psicologia.

${ }^{5}$ Escrita em primeira versão em 1966, para responder às exigências da tese de livre-docência do autor, a obra foi publicada pela primeira vez em 1974, tendo se tornado referência para várias gerações de pesquisadores no âmbito da História da Educação. Nela são cunhados os termos entusiasmo pela educação e otimismo pedagógico para explicar o espírito que caracterizou a década de 1920, assim definido pelo autor: “(...) uma atitude que se desenvolveu nas correntes de ideias e movimentos político-sociais e que consistia em atribuir importância cada vez maior ao tema da instrução, nos seus diversos níveis e tipos" (NAGLE, 2001, p. 135). O cenário da sociedade 


\section{N

ISSN: 1984-6444 | http://dx.doi.org/10.5902/1984644433299

brasileira em que ocorre a difusão das ideias escolanovistas, segundo o autor, é o de retomada dos princípios do liberalismo em conjugação com a passagem do sistema agrário-comercial para o sistema urbano-industrial e da estruturação das bases de uma sociedade de classes.

${ }^{6}$ Para um aprofundamento sobre as discussões do autor consultar: GOUVÊA, M. C. S.; GERKEN, C. H. S. Desenvolvimento humano: história, conceito e polêmicas. São Paulo: Cortez, 2010.

${ }^{7}$ A tese de Ivanete Batista dos Santos defendida em 2006 dedicou-se ao exame das produções de Edward Lee Thorndike ligadas ao ensino de Aritmética, Álgebra e Geometria. A autora traz uma discussão importante sobre os escritos de Thornike sobre Psicologia da Aprendizagem, a partir dos escritos do próprio autor.

${ }^{8}$ Dois artigos do autor Saulo de Freitas Araujo $(2003,2009)$ trazem aprofundamentos importantes quanto a biografia, fundamentos e obra de Wilhelm Wundt:

ARAUJO, S. F. A obra inicial de Wundt: um capítulo esquecido na historiografia da psicologia. Revista do Departamento de Psicologia da UFF, 15, 2, p. 63-76, 2003.

ARAUJO, S. F. Wilhelm Wundt e a Fundação do Primeiro Centro Internacional de Formação de Psicólogos. Temas em Psicologia (Ribeirão Preto), v. 17, p. 3-8, 2009. 